\title{
The Predictive Ability of the Self-Esteem scale Dimensions for Bully Victimization Among Basic School Students in the City of Ma'an, Jordan
}

\author{
Muna Ali Abu Darwish \\ Educational Sciences College, Al-Hussein Bin Talal University, Ma'an, Jordan \\ Amjad Farhan Alrekebat \\ Educational Sciences College, Al-Hussein Bin Talal University, Ma'an, Jordan \\ Ibrahim Abdullah Shoqirat \\ Education for Southern Badia Directorate - Ma'an, Jordan \\ Raed Omar Salah \\ Educational Sciences College, Al-Hussein Bin Talal University, Ma’an, Jordan
}

\begin{abstract}
The study aimed at identifying the ability of the self-esteem scale dimensions in predicting bully victimization among basic school students in the city of Ma'an in Jordan. The study examined the variations in students' levels of self-esteem and levels of bully victimization in relevance to gender, academic achievement, and birth order. The bully victimization scale and self- esteem scale were used to achieve the purposes of this study. The sample included 225 students (104 males and 121 females) from grades 6 to 9 . The results showed statistically significant negative relation between total self-esteem scale and its dimensions and the levels of bully victimization and that the dimensions of self-esteem scale explained $17.5 \%$ of variance of the degree of bully victimization. It was also revealed that family and social dimensions of self-esteem were statistically significant in predicting levels of bully victimization among the participants. Furthermore, there were statistically significant differences in students' levels of self-esteem scale in favor of males and students with "excellent" academic achievement. However, there were no statistically significant differences in the students' levels of self-esteem related to birth order. Finally, female students reported significantly higher levels of bully victimization; and that academic performance and birth order were not statistically significant.
\end{abstract}

Keywords: Self- Esteem, Bully Victimization, Basic schools students, Ma'an, Jordan.

DOI: $10.7176 / \mathrm{JEP} / 11-11-08$

Publication date: April $30^{\text {th }} 2020$

\section{Introduction}

Recently, the phenomenon of bullying has become popular among school students, the characteristics and indicators of bullying have become clear in schools. The elements of bullying process include bullies, victims, and bully-victims. Olweus (1993) was among the first scholars who pointed to and discussed the phenomenon of bullying. Bullying is a form of aggressive behavior, occurs when a child or individual is constantly and repeatedly subjected to negative behaviors that causing him pain, bullying is distinguished by the inequality of power between two individuals; one is called bully and the other one is called victim (Olweus, 1993). Abu Ghazal, (2009) defined bullying as an aggressive behavior that involves physical abuse, verbal abuse or humiliation in general. Bullying results from inequalities of power between two individuals, one is called bully and the other is called victim (Abu Ghazal, (2009).

It is clear that bullying involves bully's intention to target a victim, where the bully would continually target the victim with aggressive behavior. Bullying involves systematic abuse by the bully against the victim for no specific reason, and the aim of such repeated aggressive behavior is to humiliate and insult the victim (Rigby, 2010).. In addition Jaradat (2016) summarized the different types of bullying, into two: overt bullying that can be graphically seen in physical and verbal behaviors such as pushing, beating, using nicknames, threatening, and cunning harassment, and covert bullying where harm is done through ruining victim's relationships with others through social exclusion, and spreading rumors.

The early and current studies that discussed the bullying agreed that the participants in the bullying can be categorized into three types: bullies, victims, bully-victims, and audience. Bullying has harmful effects on the victims; these victims would suffer from low self-esteem and a sense of inferiority (Hajaj, 2018, AL-Hajaj, 2010; O'Moore \& Kirkham, 2001). In addition, the victims of bulling would suffer from poor academic performance (Atik, 2006), depression (Undheim \& Sund, 2010), feeling of loneliness, low level of social support from colleagues (Abu-Gazal, 2009; AL-Sqart, 2013). And so Gini (2008) revealed that victims had higher risk for 
conduct problems, high levels of social anxiety, fear of negative evaluation, avoidance of social situations and social skills deficits. In addition, Evans, Smokowski and Cotter (2014) concluded that cumulative bullying victimization was associated with negative developmental outcomes and poor mental health functioning. They confirmed that victims expressed increased rates of depression, anxiety, aggression, and decreased self- esteem and future optimism. The victims of bullying would exhibit several negative behaviors that might include malingering to avoid going to school and returning home, tearing down their books and clothes, exercising violence against their brothers and sisters, isolation and refusal to carry out any social or physical activity (AL-Bentan, 2019).

Self-esteem has been an important and fundamental topic that has attracted the attentions of scholars specialized in studying human and personal behavior. Self-esteem plays an integral role in shaping individuals' behaviors and in enhancing their mental health. Jaradat (2006) included the findings of some academic research that examined the roles of high or low self-esteem in individual's life. For example, high self-esteem increases their motivation to achievement and learning and makes their personality less susceptible to psychological disorders. On the other hand, low self- esteem is associated with many psychological problems including depression, anxiety and stress. Self-esteem has very important applications in shaping individuals' behaviors, Individuals with high self-esteem tend to be more self-confident, independent, accountable, and optimistic about their future (Kafafi, 2015).

\section{Previous Studies}

Rshaid (2019) investigated the differences among bullies, victims and uninvolved in self- esteem and academic achievement. The sample consisted of 641 male and female students in grades from seventh to tenth selected from two primary schools in Jordan. The results showed that both uninvolved students and bullies had significantly higher self- esteem than did victims. Also, the uninvolved students had significantly higher academic performance than did bullies or victims.

The study of Hajaj (2018) examined the differences in self-esteem and problem-solving skills among 500 male and female students in Amman, Jordan using bullying scales. The sample was categorized into three groups: bullies, victims and not involved. The results showed higher level of in self-esteem in favor of the not involved as compared to others. The study also revealed differences related to gender in favor of male students. This study recommended that bullies and victims should be identified and participate in educational and awareness programs on the dangers and effects of bulling. Furthermore, parents themselves should get engaged in the efforts that aim to encounter this phenomenon.

Tannous and Al-Khawaldeh (2014) used a training program to improve self-esteem and adjustment among students who were victims of bullying. The sample of the study consisted of 24 students from sixth, seventh, and eighth grades in Amman, Jordan. The students were divided into two groups: control and experimental group. Students in the experimental group completed a training program designed to improve their assertiveness skills. The results demonstrated that the program was effective in improving self-esteem and adaptation among the students.

A cross-sectional study by Brito and Oliveira (2013) that included 237 male and female ninth graders, in a public school in Olinda showed that the bullying spreads widely among students. In fact, $48.9 \%$ reported they were once victims of bullying. The study also revealed lower self-esteem levels among bullying victims as compared to bullies or bully-victims.

Dwairi (2013) investigated the differences between the bullying groups among both genders using the family environment scale and bullying and victimization scale so that the dimensions that predict bullying and victimization could be identified. The sample of her study included 1004 students in grades from 7 to 10 in northern Jordan. Results revealed significant differences between the means of the bullying groups. Family conflict, recreational activities and cultural- intellectual orientation predicted bully victimization among males, whereas conflict, recreational activities and organization were the graphic predictors among females.

Abdelwahab, (2011) focused on examining self-esteem dimensions that most predict violent behavior among secondary school students in Qena, Egypt. This study revealed no significant differences in the level of self-esteem due to gender, and there is a negative correlation relation of the three self- esteem dimensions of family, school, and peer to violent behavior among participants. Family then school self- esteem appeared to be the dimension that most predict the violent behavior.

Cassidy (2009) conducted a study that aimed to identify the relationship between social identity, family and school context, problem-solving, self-esteem, psychological stress, and levels of bully victimization among students. The sample of the study consisted of 461 students from Ireland. Results showed that victimization prevailed to as high as $29 \%$ percent. and that victims demonstrated high levels of emotional suffering, low level of self-esteem, higher level of harmful behaviors, and limited support from parents and teachers that restricted their ability to solve problems. There were also statistically significant associations between students' family context, social identity, and problem-solving from one side and levels of bully victimization among students from 
the other side.

In another study, Jaradat (2008) investigated the prevalence of bullying behavior and its associated factors. The sample consist of 656 from primary school students in Irbid, Jordan. The results indicated that male students are involved in bullying or becoming its victims much more than females do. Male students preferred the way back from school to practice bullying. While females preferred the class room. Results also showed significant differences in the levels of self- esteem in the bullying groups in favor of the bullies and the not involved students. It has been also found out that not involved students came from families that enjoy stronger relationships and better academic performance than bullies and victims.

A study by Al-Sarairah (2007) aimed to examine the variations of self-esteem, family and social relations, mood, leadership characteristics, and academic achievement. The sample consist of 158 male and 144 female students in Jordan. The participants were categories into three types: bullies, victims of bully, and the not involved the results revealed that there was a significant difference in students' levels of self-esteem in favor of the not involved. The results also showed significant differences in students' self-esteem between bullies and their victims in favor of bullies.

Fox and Boulton (2006) examined the relationship between problems related to social skills and the levels of peer victimization and the mediating role of friendship in that relationship. The sample consisted of 449 students. The results revealed that more social skills problems lead to higher levels of becoming victims of peer bullying and predict a high level of peer victimization along time. However, the strength of the relationship between social skills problems and the level of peer victimization was weaker among the students who had a large number of friends or students who had a popular friend. In the context of the effect of social factors on bulling in schools.

Atik (2006) examined the phenomenon of bullying and the predictors of its occurrence at some schools in Turkey. The sample of the study consisted of 742 male and female students in grades six to eight. The results indicated that bullying spread widely among students and that the victims expressed a high sense of loneliness, low social acceptance and involvement, and poor academic performance. The families of the victims were characterized by the lack of affection and the lack of parental strictness and supervision.

However, loneliness was the only significant predicting factor of bully victimization among students.

Ahmed and Braithwaite (2004) investigated the differences in parenting style, family disharmony, and some school variables, among bullies and their victims. The sample included a group of parents and 610 students selected from 32 public and private schools in the capital of Australia. The participants were between the ages of 9 and 12 . The results showed that the bullies were subjected to more authoritative parenting style than other students and the victims reported higher level of family disharmony compared to others.

In another study, O'Moore and Kirkham (2001) examined the relationship between self-concept and bullying behavior among a sample of students between the ages 8 and 18. The results showed that both victims and bullies had a lower level of self-esteem in comparison to others at the same age who had neither bullied or been bullied. Victims of bullying were less popular and were more anxious than other students and they also had a turbulent personality.

Rigby, Slee, and Cunningham (1999) conducted a study that investigated the impact of parenting patterns on peer relation among a sample of 803 male and 687 female adolescents. The results showed that there was an association between high level of parental care and adolescents' social behavior. It was also revealed that low level of parental care is associated to the levels of bullying and bully victimization among adolescents. Furthermore, over-protection pattern of parental care was significantly associated with high levels of being a bullying victim.

\section{Study Importance}

Most previous research was mostly interested in investigating the relationship between bulling and general selfesteem. However, this study is different in that it:

1- Considers more precisely the predictive ability of academic, family, personal and peer dimensions of selfesteem in predicting bully victimization, and may motivate other researchers to do so.

2- Can be useful in developing counseling and preventive programs dedicated to bullies, victims as well as parents.

\section{Study Purpose}

1 - Explore the predictive ability of self- esteem dimensions for bully victimization.

2- Identify which of these dimensions contribute more predict bully victimization.

3- Make the base for counseling programs for both students and parents.

\section{Study Questions}

1- What is the ability of self-esteem dimensions to predict bully victimization among basic school students in Ma'an, Jordan?

2- Are there any statistically significant differences, at $(\alpha=0.05)$, in students' self-esteem related to gender, 
academic achievement, and birth order?

3 - Are there any statistically significant differences, at $(\alpha=0.05)$, in bully victimization among students related to their gender, academic achievement and birth order?

\section{Method}

\subsection{Study Design}

This study is considered as a descriptive correlational study.

\subsection{Study Society and Sample}

The research community consisted of all the (2384) male and female students in grades six to nine in the public school in Ma'an Directorate of Education during the second semester of the scholastic year 2017/2018. The sample included (225) randomly chosen students representing $10 \%$ of the whole population. Table 1. Descriptive summary of participants' demographic data

\begin{tabular}{llll}
\hline Variable & Category & Frequency & Percent \\
\hline Gender & Male & 104 & 46.2 \\
& Female & 121 & 53.8 \\
& Six & & 30.7 \\
Grade & Seven & 69 & 20.9 \\
& Eight & 47 & 24.0 \\
& Nine & 54 & 24.4 \\
Grade point & Accepted & 55 & 9.8 \\
level & Good & & 16.9 \\
& Very good & 22 & 36.4 \\
& Excellent & 38 & 36.9 \\
Birth order & First born & 82 & \\
& Middle children & 83 & 29.8 \\
& Youngest & 67 & 53.8 \\
& & 121 & 16.4 \\
\hline
\end{tabular}

\subsection{Study Scales}

In order to accomplish the goals of this study, two scales were used:

\subsubsection{Bully victimization Scale}

This scale was developed by Jaradat (2008). It includes (10) items scoring from 0 to 7 . Its surface validity was verified by experts from different Jordanian universities. Pearson correlation coefficient was used to verify the construct validity. Values ranged from $(0.464$ to 0.846$)$ which is statistically significant at $(\alpha \leq 0.05)$. Cronbach alpha coefficient was used to verify its reliability (value $=0.83$ ).

\subsubsection{Self-esteem scale}

This scale was developed by Al-Naimat, (2015) and included 54 items that go under five dimensions: academic, social, family, personal, and peers and answered by checking" yes or no"

The values of Pearson correlation coefficients for the dimensions of the scale ranged from (0.528 to 0.892.) which indicated a statistical significance at $(\alpha \leq 0.01)$. Table 2 shows the degree of correlation coefficients between each dimension of the self-esteem scale and the overall scale.

Table 2. Correlation between each dimension of the self-esteem scale and the overall scale

\begin{tabular}{llc}
\hline Number & Dimension & Degree of correlation \\
\hline 1 & Academic dimension & .892 \\
2 & Social dimension & .843 \\
3 & Family dimension & .528 \\
4 & Personal dimension & .639 \\
5 & Peers dimension & .642 \\
\hline
\end{tabular}

The reliability of the scale was verified by using Cronbach alpha coefficient: value $=0.77$

\section{Results and discussion}

Results of the First Question: What is the ability of self-esteem dimensions to predict bully victimization among basic school students in Ma'an, Jordan?

To answer this question, Pearson correlation coefficient were used, table 3 shows the result. 
Table 3. Ccorrelation coefficients between self-esteem dimensions and bully victimization

\begin{tabular}{cllllll}
\hline $\begin{array}{c}\text { Bully } \\
\text { victimization }\end{array}$ & Self-esteem & $\begin{array}{l}\text { Academic } \\
\text { dimension }\end{array}$ & $\begin{array}{l}\text { Social } \\
\text { dimension }\end{array}$ & $\begin{array}{l}\text { Family } \\
\text { Dimension }\end{array}$ & $\begin{array}{l}\text { Social } \\
\text { dimension }\end{array}$ & $\begin{array}{l}\text { Peers } \\
\text { Dimension }\end{array}$ \\
\cline { 2 - 7 } & $-0.387^{* *}$ & $-0.296^{* *}$ & $-0.358^{* *}$ & $-0.358^{* *}$ & $-0.194^{* *}$ & $-0.286^{* *}$ \\
\hline
\end{tabular}

** Significant at $\alpha \leq 0.01$

These results indicate that a higher level of self-esteem decreases the chances of becoming a bully victim. This emphasizes how influential self-esteem is as a psychological variable that enables individuals and enhances their self- confidence. On the contrary, individuals with low self- esteem are passive, unable to encounter difficulty situations. More importantly, they are at a greater risk of being involved in bullying situations victims. These findings are consistent with results introduced by (O'Moore \& Kirkham, 2001; AL-Sarairah, 2007; Jaradat, 2008; Brito \& Oliveira, 2013).

In order to identify the ability of the dimensions of self-esteem to predict bullying among students, regression analysis was used. Table 4 and 5 show the results of the multiple regressions.

Table 4. Results of multiple regression analysis of the self-esteem scale predictive ability of bully victimization

\begin{tabular}{llccccc}
\hline \multicolumn{1}{c}{ Model } & R Square & $\begin{array}{c}\text { Sum of } \\
\text { Squares }\end{array}$ & $\begin{array}{c}\text { Degree of } \\
\text { Freedom }\end{array}$ & $\begin{array}{c}\text { Mean } \\
\text { Square }\end{array}$ & F & Sig. \\
\hline Regression & 0.175 & 4182.788 & 5 & 836.558 & $* * 9.303$ & 0.00 \\
Residual & & 19693.995 & 219 & & & \\
Total & & 23876.782 & 224 & 89.927 & & \\
\hline
\end{tabular}

* Significant at $\alpha \leq 0.01$; Correlation coefficient $(\mathrm{R}=0.419)$; Coefficient of determination (R-squared, $\mathrm{R}^{2}=0.175$ ).

Results in table 4 reveal that all self- esteem dimensions are statistically significant in predicting bully victimization $(F=9.303)$ at level of 0.00 at $\alpha \leq 0.01$. It was also revealed that the self- esteem scale dimensions together explain $(17.5 \%)$ of becoming a bully victim among the participants. In order to identify which of the selfesteem dimensions signifies more in bully victimization.

Multiple regression (Beta) was used to identify which dimension of the self-esteem scale predict bully victimization more than the others. Result is shown in table 5.

Table 5 . The results of multiple regression to identify the predictive ability of the self-esteem dimensions for bully victimization

\begin{tabular}{llllll}
\hline $\begin{array}{l}\text { Dimensions of } \\
\text { Self-esteem }\end{array}$ & B & Std.error & Beta & (t) & Sig. \\
\hline Academic dimension & -0.342 & 0.373 & -0.075 & -0.917 & 0.360 \\
Social dimension & -0.963 & 0.457 & -0.194 & $-2.108^{*}$ & 0.036 \\
Family dimension & -1.075 & 0.421 & -0.204 & $-2.551 *$ & 0.011 \\
Social dimension & 0.536 & 0.484 & 0.086 & 1.108 & 0.269 \\
Peers dimension & -0.701 & 0.566 & -0.095 & -1.238 & 0.217 \\
\hline
\end{tabular}

* Significant at $\alpha \leq 0.01$.

Data in Table 5 shows that family and social dimensions have a stronger statistical significance in bully victimization than the other three dimensions do based on the standardized coefficients (Beta),(t) values and the level of significance ( $\mathrm{sig}$ ). This significant Correlation of social self-esteem can be attributed to the fact that selfesteem basically involves how the individual conceptualize what others think of him; and that lower social selfesteem is related to the individual's inability to socialize or maintain his relation with others as he might feel unacceptable by others

This result was indicated by Atik (2006) who reported a significant relation between weaker levels of social interaction and acceptance and becoming a bully victim. Fox and Boulton (2006). also argued that problems in social skills predicted stronger possibilities of bully victimization. Abu Ghazal (2009) indicated that bully victims reported lower social support and a feeling of loneliness. AL- Shoubaki (2012) emphasized that loneliness is generally associated with individual's feeling of inferiority, lower self- confidence in addition to inability to socialize with others or maintain strong relations with them. This all emphasizes the importance of individuals' healthily social life and that any disorders it involves create higher risks for victimization.

This study reveals that victims suffer from a lower family self- esteem. It's may be that they came from families that have poorer economic or social conditions that might be sometimes accompanied by in appropriate parenting style. Similar results were reported by Rigby, Slee and Cunningham (1999) which showed that a lower level of parental care lead to bully victimization and is supported by, Al-Sarairah (2007) and Jaradat (2008) that emphasized the role of family relationships in bully victimization. The results of the current study also find support by other researchers who concluded that family environment and watching family violence are predictive elements for bully victimization (Dwairi, 2013. Hemphill et al. 2012 Abdelwahab, 2011). In addition, Brito and Oliveira (2013), for example, recommends investigating family dynamics as an element related to bullying.

Result of the Second Question: Are there any statistically significant differences, at $(\alpha=0.05)$, in self-esteem 
related to gender, academic achievement, and birth order?

To answer this question, means, standard deviation were calculated. Table 6 shows these results.

Table 6. Means, standard deviations, adjusted means and standards errors for students' scores in self-esteem scale gender, academic achievement, and birth order

\begin{tabular}{|c|c|c|c|c|c|c|}
\hline Variable & Category & Number & Mean & SD & $\begin{array}{l}\text { Adjusted } \\
\text { mean }\end{array}$ & $\begin{array}{l}\text { Standard } \\
\text { error }\end{array}$ \\
\hline \multirow[t]{2}{*}{ Gender } & \multirow{2}{*}{$\begin{array}{l}\text { Male } \\
\text { Female }\end{array}$} & \multirow{2}{*}{$\begin{array}{l}104 \\
121\end{array}$} & 37.62 & 6.591 & 36.494 & 751. \\
\hline & & & 31.87 & 6.909 & 31.208 & 703. \\
\hline \multirow{4}{*}{$\begin{array}{l}\text { academic } \\
\text { achievement }\end{array}$} & Accepted & 22 & 29.77 & 8.395 & 30.791 & 1.442 \\
\hline & Good & 38 & 32.97 & 8.458 & 33.306 & 1.122 \\
\hline & \multirow{2}{*}{$\begin{array}{l}\text { Very good } \\
\text { Excellent }\end{array}$} & 82 & 34.27 & 6.833 & 34.796 & 782. \\
\hline & & 83 & 36.76 & 6.187 & 36.511 & 748. \\
\hline \multirow[t]{3}{*}{ Birth order } & First born & 67 & 34.96 & 7.646 & 33.397 & 872. \\
\hline & Middle children & 121 & 33.98 & 7.331 & 33.861 & 656. \\
\hline & Youngest & 37 & 35.57 & 6.789 & 34.295 & 1.135 \\
\hline
\end{tabular}

The data in Table 6 shows that there were differences between the means of students' responses to self-esteem scale related to gender, academic achievement, and birth order. In order to examine whether such differences were significant, "three way-ANOVA" was conducted. Table 7 shows the results.

Table 7. Results of Three way-ANOVA of students' responses to self-esteem scale related to gender, academic achievement and birth order

\begin{tabular}{llcccc}
\hline Source & $\begin{array}{l}\text { Sum of } \\
\text { Squares }\end{array}$ & $\begin{array}{c}\text { Degree of } \\
\text { Freedom }\end{array}$ & $\begin{array}{c}\text { Mean of } \\
\text { Square }\end{array}$ & F & Sig. \\
\hline Gender & 1497.081 & 1 & 1497.081 & 34.260 & 0.000 \\
Academic achievement & 651.275 & 3 & 217.092 & 4.968 & 0.002 \\
Birth order & 20.029 & 2 & 10.014 & 0.229 & 0.795 \\
Error & 9526.113 & 218 & 43.698 & & \\
Total & 280311.000 & 225 & & & \\
Corrected total & 12056.062 & 224 & & & \\
\hline
\end{tabular}

Table 7 shows that there were statistically significant differences in students' levels of self-esteem related to gender and academic achievement. Such results were reported based on the values of $\mathrm{F}$ and the associated levels of significance. Differences related to gender were significant in favor of males $(M=37.62)$ while female reported $(M=31.87)$. Such a result might be attributed to males' tendency to demonstrate domination, competence and eagerness to prove masculinity in a society that reinforces these feelings and gives males better opportunities and experiences to develop their personality and self- esteem, but doesn't give such opportunities to females who have to comply with strict social criteria that make them feel inferior. The findings in Hajaj (2018) support this result while Abdelwahab (2011) did not show any differences related to gender.

To identify self-esteem differences related to academic achievement, Scheffe test was used. Table 8 shows the results.

Table 8. Scheffe test results of differences in self-esteem level related to academic achievement

\begin{tabular}{lccccc}
\hline Academic Achievement & Mean & Accepted & Good & Very good & Excellent \\
\hline Accepted & 30.791 & - & -2.515 & -4.005 & $-5.720 *$ \\
Good & 33.306 & 2.515 & - & -1.490 & $3.205-$ \\
Very good & 34.796 & 4.005 & 1.490 & - & $1.715-$ \\
Excellent & 36.511 & $5.720 *$ & 3.205 & 1.715 & - \\
\hline
\end{tabular}

The data in Table 8 shows that there were statistically significant differences in students' levels of self-esteem related to academic achievement in favor of "excellent". Usually, such findings might be explained by the fact that students with higher levels of academic achievement have a higher level of self-efficacy and ability to achieve, which will certainly enhance their feeling of self- esteem. This result is consistent with Jaradat (2011)

The results didn't show any statistically significant differences in students' levels of self-esteem related to birth order.

Result of the third question: Are there statistically significant differences, at ( $\alpha=0.05)$, in bully victimization among students related to their gender, academic achievement and birth order?

To identify any differences in bully victimization related to the three variables of this study, means and standard deviation were calculated. Results are shown in table 9 
Table 9. Means, standard deviations, adjusted means and standards errors for students' scores in bully victimization scale based on their gender, Academic achievement, and birth order

\begin{tabular}{lllllll}
\hline Variable & Category & Number & Mean & SD & $\begin{array}{l}\text { Adjusted } \\
\text { mean }\end{array}$ & $\begin{array}{l}\text { Standard } \\
\text { error }\end{array}$ \\
\hline Gender & Male & 104 & 7.14 & 7.780 & 7.296 & 1.164 \\
& Female & 121 & 10.24 & 11.939 & 10.119 & 1.089 \\
& & & 9.86 & 9.326 & 8.955 & 2.234 \\
Academic & Accepted & 22 & 10.74 & 12.768 & 10.150 & 1.739 \\
achievement & Good & 38 & 9.18 & 11.043 & 8.635 & 1.211 \\
& Very good & 82 & 7.28 & 8.387 & 7.090 & 1.159 \\
& Excellent & 83 & & & & 1.352 \\
Birth order & First born & 67 & 9.12 & 11.116 & 9.914 & 1.016 \\
& Middle children & 121 & 9.37 & 10.708 & 9.214 & 1.759 \\
\hline
\end{tabular}

Data in Table 9 shows clear differences in the means. To ensure that these differences are significant, the "three way-ANOVA" was used. Table10 shows the results.

Table 10. Results of Three way-ANOVA of students' responses to bully victimization scale according to gender, academic achievement and birth order

\begin{tabular}{llllll}
\hline Source & $\begin{array}{l}\text { Sum of } \\
\text { Squares }\end{array}$ & Degree of Freedom & Mean Square & F & Sig. \\
\hline Gender & 427.236 & 1 & 427.236 & $4.074 *$ & 0.045 \\
academic achievement & 254.066 & 3 & 84.689 & 0.808 & 0.491 \\
Birth order & 208.743 & 2 & 104.372 & 0.995 & 0.371 \\
Error & 22861.202 & 218 & 104.868 & & \\
Total & 41336.000 & 225 & & \\
Corrected total & 23876.782 & 224 & & \\
\hline
\end{tabular}

Results in Table 10 show a statistically significant difference in bully victimization in favor of females based on $\mathrm{F}$ values and the associated levels of significance $(M=10.24)$ and $(M=7.14)$ for males. It is also clear that differences related to academic achievement and birth order are not statistically significant. Differences related to gender are higher in favor of females may be related to social well- established considerations where they have to be fully obedient as a part of her acceptable social role. This leads to a feeling of helplessness and later higher degree to becoming victims contrary to males who receive the support to defend themselves and refuse defeat. However, this contradicts Jaradat (2008) that indicated higher levels in favor of males both as bullies as well as victims. Academic achievement and birth order are insignificant may be for many reasons. For example, victimization is the result of the conditions one lives and strengthen his power but not directly his academic performance. Bullies simply target any other student regardless his achievement. Birth order is closely related to parenting style and family environment and culture which still requires more investigation.

\section{Conclusion}

This study was particularly interested in exploring the predictive ability of the self-esteem scale dimensions for bully victimization in school environment at a particular age. It was found out that family and social self- esteem dimensions were more significant predictors than the other dimensions. The main focus of this study was the bully victims both males and females. However, females reported higher rates of victimization which finds support in other studies. Authors suggest that this research paves the way for developing programs that involve bully victimization, families, counselors and teachers in any precaution effort to encounter this phenomenon.

\section{Recommendations}

In the light of these results, the researchers recommend:

- Activating educational and psychological counseling services to provide training programs to encounter and reduce the phenomenon of bullying in general.

- Designing and developing counseling programs that involve social and self development skills that serve both the bullies and victims

- Activating family counseling services that include training parents on how to protect their children against bullying.

\section{References}

Abdelwahab, M. (2011). Dimension of Self- esteem Which Predict Violence of Secondary School Students, Journal of Arabic Studies in Psychology, Vol 10, No,(4) 701- 752. 
Abu-Ghazal, M. (2009). Bullying as Related to Loneliness and Social Support, Jordan Journal of Educational Sciences, Vol 5, No.(2), 89- 113.

Ahmed, E., and Braithwaite, V., (2004). Bullying and Victimization Cause for both Families and Schools, Social Psychology of Education, 7: 35- 54. https://doi.org/10.1023/B:SPOE.0000010668.43236.60

AL-Bentan, M. (2019). Social Factor Leading to Bullying Behavior among Students in Intermediate School in Hail Region, Journal of College of Basic Education for Educational and Human Sciences, No. (42), 103130 .

AL-Hajjaj, L. (2010). Relationship Between Bullying, Social Values, Awaking Conscience and a Sense of Inferiority among Bullies Students in Higher Basic Stage Schools in Tafila, unpublished Master Thesis, Mutah University, AL- Karak, Jordan.

AL- Naimat, K. (2015). Constructing of Multidimensional Self-Esteem Scale, Ph.D, Dissertation, University of Jordan, Amman, Jordan.

AL-Sarairah, M. (2007). The Differences in Self- esteem, Family Relationship, Social Relationship, Mood, Leadership, and Academic Achievement among Bullies, Their Victims, and Normal Students in The Adolescence Stage, Ph.D, Dissertation, Amman Arab University, Amman, Jordan.

AL- Shoubaki, N. (2012). The Effect of Group Guidance Program on Problem Solving in Reducing Isolation Behavior among Secondary Stage Female Students, Journal of Faculty of Education, Ain Shams University (36), 2, 653- 680.

AL-Sqarat, M. (2013). The Two Levels of Psychological loneliness and Self- Concept among the Victims of Bullying in the School of Tafila Directorate of Education, unpublished Master Thesis, Mutah University, ALKarak, Jordan.

Atik, G. (2006).The Role of Locus of Control, Self- Esteem, Parenting style, Loneliness, and Academic Achievement in Predicting Bullying among Middle School Students, unpublished Master Thesis, Middle East Technical University, Turkey.

Brito, C, Oliveira, M. (2013). Bullying and self-esteem in adolescents from public schools, J Pediatr (Rio J), 89 (6): 601- 607. https://doi.org/10.1016/j.jped.2013.04.001

Cassidy, T. (2009). Bullying and Victimization in School Children: The role of social identity, problem- solving style, and family and school context. Social Psychology Educational, 12, 63-76. https://doi.org/10.1007/s11218-008-9066-y

Dwairi, W. (2013). Bullying and Victimization and Their Relationship to Family Environment in a Sample of Primary School Students in the Governorate of Irbid, Ph. D, Dissertation, Yarmouk University.

Evans, C,. Smokowsi, P,. Cotter, K,. (2014). Cumulative bulling Victimization: An investigation of the doseresponse relationship between Victimization and the associated mental health outcomes, social supports, and school experiences of rural adolescents, Children and Youth Services Review,(44),256-264. http://dx.doi.org/10.1016/j.chilyouth.2014.06.021

Fox, c. and Boulton, M. (2006). Friendship as a Moderator of the Relationship between Social Skills Problems and Peer Victimization, Aggressive Behavior, 32 (2): 110-121. https://doi.org/10.1002/ab.20114

Gini, G. (2008). Associations between bulling behavior, psychosomatic complaints, emotional and behavioral problems, Journal of Paediatrics and Child Health, 44(9), 492-497. https://doi.org/10.1111/j.14401754.2007.01155.x

Hajaj, Z. (2018). Differences in Self- Esteem and Problem-Solving Skill among Bullies, their Victims and Normal Students in the Primary Stage, Dirasat: Educational Sciences, Vol, 45, No. 4, (6).

Hemphill, S,. Kotevski, A,.Tollit, M,. Smith, R, Herrenkohl, T,. Toumbourou, J,. and Catalano, R,.(2012). Longitudinal predictor of cyber and traditional bulling perpetration in Australian secondary school students, Journal of Adolescent Health, 51(1) 59- 65. https://doi.org/10.1016/j.jadohealth.2011.11.019

Jankauskiene, R,. Kardelis, K,. Sukys, S,. And Kardeliene, L. (2008). Association between school bulling and psychosocial factors, Social Behavior and Personality, 36 (2), 145-162. https://doi.org/10.2224/sbp.2008.36.2.145

Jaradat, A. (2016). Differences in Bullying and Victimization between Optimistic Adolescent and those who are not optimistic. Dirasat: Educational Sciences, Vol, 43, (1), 549-560. https://doi.org/10.12816/0030015

Jaradat, A. (2011). The Role of Family Relationship, Academic Achievement, Grade, Family Size and Gender in the Prediction of Self-Esteem among Adolescents, Educational Journal, No. 99, (1), Kuwait University.

Jaradat, A. (2008). Bullying among Primary School Students: Prevalence and Correlates, Jordan Journal of Educational Sciences, Vol, 4, No (2), 109- 124

Jaradat, A. (2006). The Relationship between Self-Esteem and Irrational Attitudes in University Students, Jordan Journal of Educational Sciences, Vol, 2, No (3), 143-153.

Kafafi, A. (2015). Developmental Psychology: Psychology of Childhood and Adolescence, 2Ed, Dar Al Fikr, 
Amman, Jordan.

Olweus, D. (1993), Bullying at School: what we know and what we can do? Cambridge, MA: Blakwell Publishers.

O'Moore, M. and Kirkham, C. (2001). Self- Esteem and its relationship to bullying behavior. Aggressive Behavior, 27(4), 269- 283.

Rigby, K. (2010), Bullying Intervention in School: six basic approach, Camberwell: Acer press.

Rigby, K., Slee, P., \& Cunningham,R. (1999). Effect of Parenting on the Peer Relation of Australia Adolescent, The Journal of Social Personality, 139 (3) 387.388 https://DOI.org/10.1080/00224549909598395

Rshaid, A, M (2019). Bulling Behaviors, Self- Esteem and Academic Achievement among Jordanian School Students. PEOPLE: International Journal of Social Sciences,5 (1) 576- 586. DOIhttps://dx.doi.org/10.20319/pijss.2019.51.576586

Tannous, A. and AL-Khawaldeh, M. (2014). Effectiveness of Assertiveness Training in Improving Self Esteem and Adjustment among Victims of Bullying Students. Dirasat: Educational Sciences, Vol, 41, (1), $421-444$.

Undheim, A,. and Sund, A,. (2010). Prevalence of bullying and aggressive behavior and their relationship to mental health problems among 12- 15 year - old Norwegian adolescents, Eur Child Adolescent Psychiatry, 19, 11, 803-811.

https://doi.org/10.1007/s00787-010-0131-7 